\title{
Numerical Study on the Flow Length in an Injection Molding Process with an External Air-Heating Step
}

\author{
Thanh Trung Do*, Pham Son Minh*, Tran Minh The Uyen*, Pham Hoang \\ The* \\ * HCMC University of Technology and Education, Vietnam
}

\begin{abstract}
In this study, an external gas-assisted mold temperature control combined with water cooling was applied to achieve rapid mold-surface temperature control for observing the melt flow length in the thin-wall injection molding process. Variable part-thickness values of $0.2 \mathrm{~mm}, 0.4 \mathrm{~mm}$, and $0.6 \mathrm{~mm}$ were used. Through a simulation and experiment, the injection molding process was achieved by using ABS and stamp insert temperatures ranging from 30 to $150{ }^{\circ} \mathrm{C}$. In the simulation, when the stamp temperature was raised from 90 to $150{ }^{\circ} \mathrm{C}$ with part thickness of $0.2 \mathrm{~mm}, 0.4 \mathrm{~mm}$, and $0.6 \mathrm{~mm}$, the melt flow length increased by approximately $25.0 \%, 19.6 \%$, and $12.8 \%$, respectively. When the stamp temperature was higher than the glass-transition temperature of $\mathrm{ABS}$, the improvement in the melt flow length was clearer, especially in the thinner part. In the experiment, the positive effect of stamp temperature was demonstrated; however, the improvement in the melt flow length was slightly different compared with the simulation owing to the heat transfer between the hot stamp and the environment.
\end{abstract}

Keywords - injection molding, flow-length-to-thickness ratio, heat-transfer coefficient, external air heating

\section{INTRODUCTION}

In the field of dynamic mold-temperature control for injection molding, external air heating is one of the fastest methods for heating the mold surface. Consequently, this method has received significant attention from researchers. In the field of plastic manufacturing, as products are becoming thinner and smaller, it is becoming difficult to manufacture such controls using conventional injection molding (CIM) because in thin parts, heat is rapidly transferred from a melt to a mold wall. Increasing the mold temperature, melt temperature, or packing pressure increases the cycle time. Thinwall parts are defined in two ways: 1) a part with a thickness below $1 \mathrm{~mm}$ across an area greater than 50 $\mathrm{cm}^{2}[1,2]$ and 2) a flow-length-to-thickness (L/t) ratio greater than $100: 1$ or $150: 1[3,4]$. To fill a cavity in an extremely short time before the skin layer forms in thin-wall parts, injection-machine manufacturers have developed machines for highspeed injection; this process is called high-speed injection molding (HSIM) [5, 6]. The purpose of performing HSIM is to fill a cavity within an extremely short time. Therefore, a high injection pressure, a stable controller, and rigid steel are necessary for an injection machine and a mold. However, HSIM has some disadvantages in terms of cost because both the injection molding machine and mold are expensive.

Another method for improving an injectionmolded part involves the application of a high injection pressure and mold temperature during injection for minimizing part thickness. However, it is difficult to maintain a high mold temperature during the filling process while lowering the mold temperature to below the deflection temperature during the post-filling process without greatly increasing the cycle time and energy consumption. To solve this problem, a variety of dynamic moldtemperature controls (DMTC) have been explored in recent years. Their purpose is to eliminate the frozen layer and ideally produce a hot mold during the filling stage and a cold mold for cooling. The most inexpensive way to achieve a high mold temperature is to use cooling water at temperatures as high as 90 or $100{ }^{\circ} \mathrm{C}[8]$.

Another heating method is local mold heating using an electric heater [9]; it is sometimes used to assist high mold temperature control. However, this method incurs additional design and tool costs. Furthermore, electrical heating is usually used as auxiliary heating and is limited to moldtemperature increases of the order of roughly several tens of degrees Celsius.

Meanwhile, mold surface heating techniques such as induction heating, high-frequency proximity heating, and gas-assisted mold temperature control (GMTC) can provide sufficient heating rates without significant increases in the cycle time. Recently, we conducted a systematic study on mold surface heating and mold surface localization heating of the processing characteristics. In this study, an external gas-assisted mold temperature control (Ex-GMTC) combined with water cooling was applied to achieve rapid mold- 
surface temperature control for observing the melt flow length in the thin-wall injection molding process.

\section{SIMULATION AND EXPERIMENTAL METHOD}

GMTC is a new technique in the field of mold-temperature control. It can rapidly heat and cool the cavity surface during the injection molding process. In general, the purpose of mold-temperature control is to increase the mold surface temperature to the target temperature before the filling of melt and to cool the melt to the ejection temperature. In this research, the Ex-GMTC system comprised a GMTC controller, hot-gas generator system (including an air compressor, an air drier, a digital volumetric-flow controller, and a high-efficiency gas heater), and water-mold temperature controller, as shown in Fig. 1.

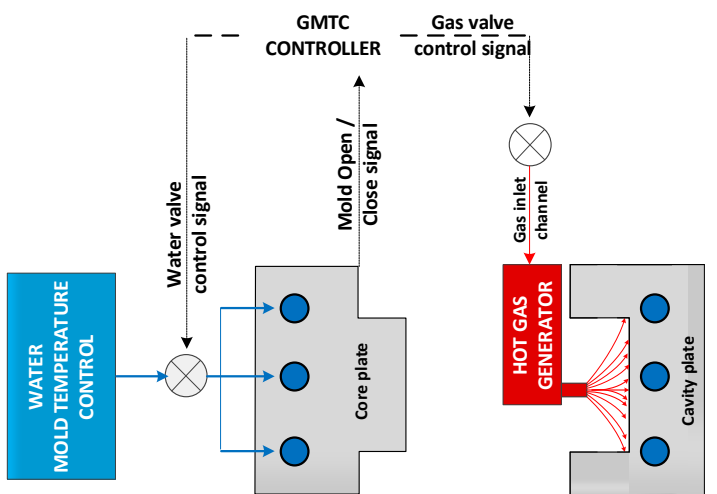

Figure 1. The Ex-GMTC system

The hot-gas generator consists of an air compressor, an air dryer, a gas valve for volumetricflow control, and a high-efficiency gas heater. The function of the high-power hot-gas generator system is to support a heat source that provides a flow of hot air of up to $500{ }^{\circ} \mathrm{C}$ at an inlet gas pressure of up to 7 $\mathrm{MPa}$. For the coolant system, a mold-temperature control was used for providing water at a defined temperature to cool the mold after the filling process and to warm the mold to the initial temperature at the beginning of the process. The valve system was used to control the water for cooling channels and the air for the heating stage. To both control and observe the temperature at the cavity surface, three temperature sensors were used to obtain the realtime mold temperature and to provide feedback to the GMTC controller.

In this study, hot gas is used as a heating source to increase the cavity surface temperature of the injection mold. For the heating operation, first, by opening the mold, two mold plates are moved to the opening position (Fig. 2, Step 1). Second, the hot-gas drier is moved to the heating position, as shown in Fig. 2, Step 2. Then, air is heated when it flows through the gas drier, and the outside of the gas drier provides hot air, which directly contacts the cavity surface. This hot gas heats the cavity surface to the target temperature (Fig. 2, Step 2). Third, when the cavity surface is heated to the target temperature, the mold completely closes in preparation for the melt-filling process (Fig. 2, Step $3)$.

In this paper, the gas drier, which has a size of $240 \mathrm{~mm} \times 100 \mathrm{~mm} \times 40 \mathrm{~mm}$, is shown in Fig. 3 . A gas channel with a width of $5 \mathrm{~mm}$ and depth of 10 $\mathrm{mm}$ is cut inside the gas drier. The heating area of the mold cavity is inserted using a stamp with a size of $175 \mathrm{~mm} \times 12 \mathrm{~mm}$. The mold, the stamp insert, and the temperature-measurement points are shown in Fig. 4. In both the simulation and experiment, the position of all systems during the heating stage is shown in Fig. 5. For observing the heating effect of Ex-GMTC on the melt-flow length, three partthickness values $(0.2,0.4$, and $0.6 \mathrm{~mm})$ of ABS are used. In addition, a numerical study is conducted for all the cases. The simulation is performed using the Moldex software. In both the simulation and experiment, before the melt is filled into the cavity, the stamp insert is heated by the Ex-GMTC system to target temperatures of $30,60,90,120$, and 150 ${ }^{\circ} \mathrm{C}$. The injection molding process is controlled with the same value for all the cases in the experiment and simulation. The details of the parameters used are shown in Table 1 .

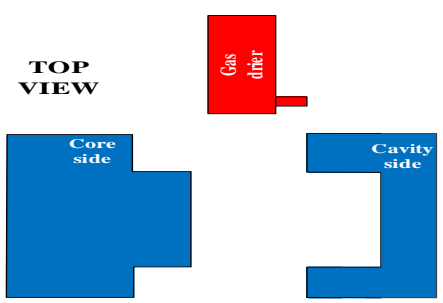

Step 1: Mold Open Position

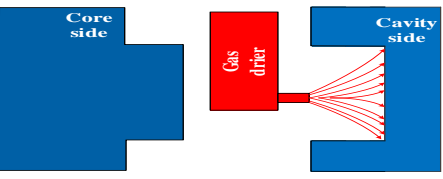

Step 2 (Heating Position) Hot gas flow passes and heats the

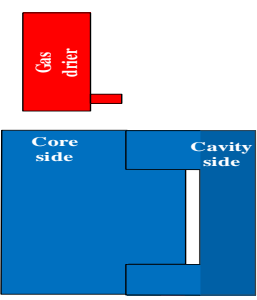

Step 3 (Molding Position) Close Mold to Molding

Figure 2. Mold position in the heating stage of the GMTC process. 


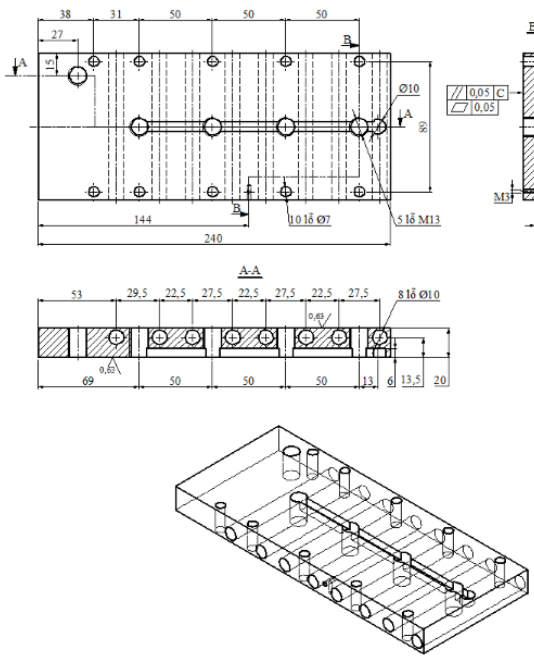

ISOMETRC VIEN

Figure 3. The gas drier
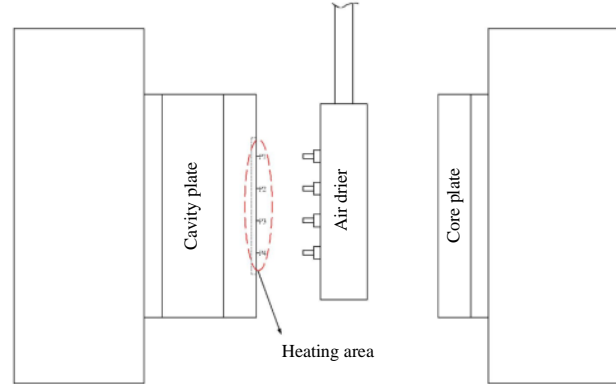

Figure 4. Heating position of Ex-GMTC

\section{RESULTS AND DISCUSSIONS}

In this study, the part thicknesses were in the range of thin-wall injection molding, which means that the heat in ABS could more easily be dissipated by the mold wall. By comparing with the same time for melt flow at a lower mold temperature, the freeze layer seriously prevented the melt from flowing [1-3]. Conversely, at a higher mold temperature, the freeze layer was reduced; as a result, the melt flow was farer $[5,6]$. Therefore, owing to the effect of the freeze layer, the mold temperature was increased by the hot air, which reduced the heat transfer from the melt to the mold volume and resulted in a longer flow length.

In this study, the melt of ABS was filled into cavity at a melt temperature of $225{ }^{\circ} \mathrm{C}$, mold temperature of $30{ }^{\circ} \mathrm{C}$, and injection pressure of 343 $\mathrm{MPa}$; the heating target of stamp temperature was varied from $30{ }^{\circ} \mathrm{C}$ to $150{ }^{\circ} \mathrm{C}$. ABS has a glasstransition temperature of $105{ }^{\circ} \mathrm{C}$. After the molding process was finished, the melt-flow length was measured based on the length of molded part. For observing the effect of stamp temperature on the ability of melt filling, three part thicknesses were applied. In each type of case, the molding process was performed for 10 cycles to achieve a stable

stage. Then, in the next 10 cycles, the molding part was collected and their measured lengths were used for comparison and discussion.

The lengths of the parts under different stamp temperatures are shown in Figs. 5 and 7 and Table 2. According to the simulation results, when the stamp temperature was lower than the glass-transition temperature of $\mathrm{ABS}$, the melt-flow length did not vary clearly. However, when the stamp temperature was higher, the variation in the melt-flow was more pronounced in the thicker part and the variation was clearer. When the stamp temperature was raised from 90 to $150{ }^{\circ} \mathrm{C}$ at part thicknesses of $0.2 \mathrm{~mm}, 0.4$ $\mathrm{mm}$, and $0.6 \mathrm{~mm}$, the melt flow length increased by approximately $25.0 \%$, $19.6 \%$, and $12.8 \%$, respectively. The flow-length measurements show that in the thinner part, the effect of the stamp temperature was more pronounced owing to the fact that the effect of the freeze layer was more in the inner-wall product.

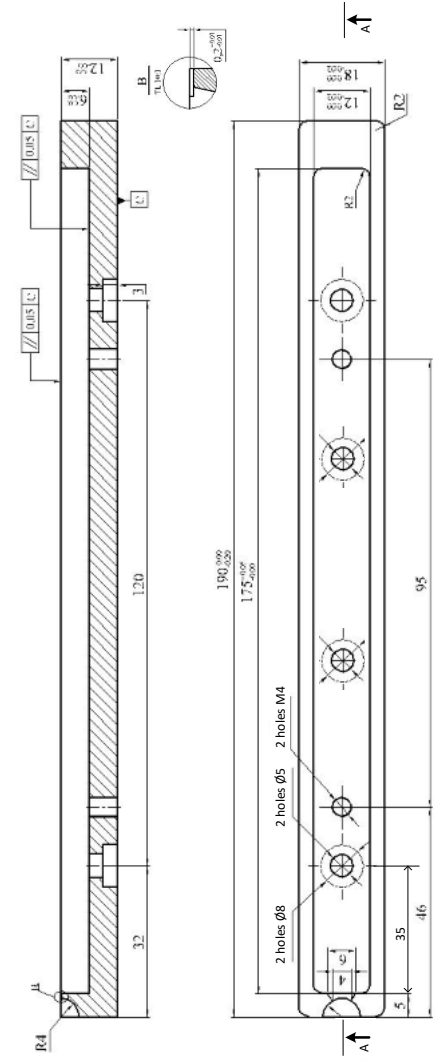

Figure 5. Mold cavity used in the experiment

Table 1. Simulation and experimental parameters

\begin{tabular}{|l|c|}
\hline Inlet air temperature & $30^{\circ} \mathrm{C}$ \\
\hline Outlet air temperature & $450{ }^{\circ} \mathrm{C}$ \\
\hline Air density & $1.185 \mathrm{~kg} / \mathrm{m}^{3}$ \\
\hline Specific heat of air & $1004 \mathrm{~J} / \mathrm{kg}^{*} \mathrm{~K}$ \\
\hline Thermal expansion of air & $0.003356 \mathrm{~K}^{-1}$ \\
\hline Air pressure & $1 \mathrm{~atm}$ \\
\hline
\end{tabular}




\begin{tabular}{|l|c|}
\hline $\begin{array}{l}\text { Initial temperature of the stamp } \\
\text { insert }\end{array}$ & $30{ }^{\circ} \mathrm{C}$ \\
\hline Density of the stamp insert & $2702 \mathrm{~kg} / \mathrm{m}^{3}$ \\
\hline Specific heat of the stamp insert & $903 \mathrm{~J} / \mathrm{kg} * \mathrm{~K}$ \\
\hline $\begin{array}{l}\text { Heat-transfer coefficient of the } \\
\text { stamp insert }\end{array}$ & $237 \mathrm{~W} / \mathrm{m} * \mathrm{~K}$ \\
\hline $\begin{array}{l}\text { Heat-convection coefficient } \\
\text { between the mold and air }\end{array}$ & $2340 \mathrm{~W} / \mathrm{m}^{*} \mathrm{~K}$ \\
\hline Simulation type & Transient \\
\hline Time of heating & $\begin{array}{c}0 \mathrm{~s} \rightarrow 30 \mathrm{~s} \\
\text { (step 5 s) }\end{array}$ \\
\hline
\end{tabular}

In the experiment, a positive effect of the stamp temperature was observed; however, the improvement in the melt-flow length was slightly than that in the simulation. The comparison between the melt-flow lengths measured in the simulation and experiment at various part thicknesses are shown in Figs. 8-10. These results show that the melt-flow lengths obtained at low stamp temperatures are similar in both the simulation and experiment. However, at high stamp temperatures, the simulation value is higher than the experimental value, especially in the case of the thinner part. This is because the heat transfer from the hot stamp to the environment, which causes rapid decreases in the stamp temperature after the completion of the airheating process. This effect was ignored in the simulation. Thus, in the experiment, the injection process was achieved with a stamp temperature that was lower than that in simulation; thus, a smaller melt-flow length was obtained in the experiment.
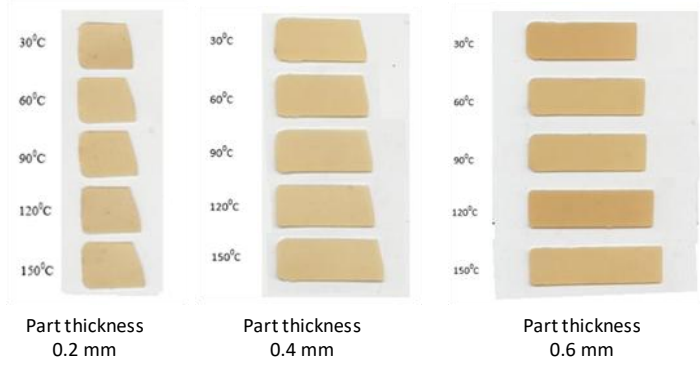

Figure 6. Melt-flow lengths measured in the experiment with the stamp temperature varying from 30 to $150{ }^{\circ} \mathrm{C}$.

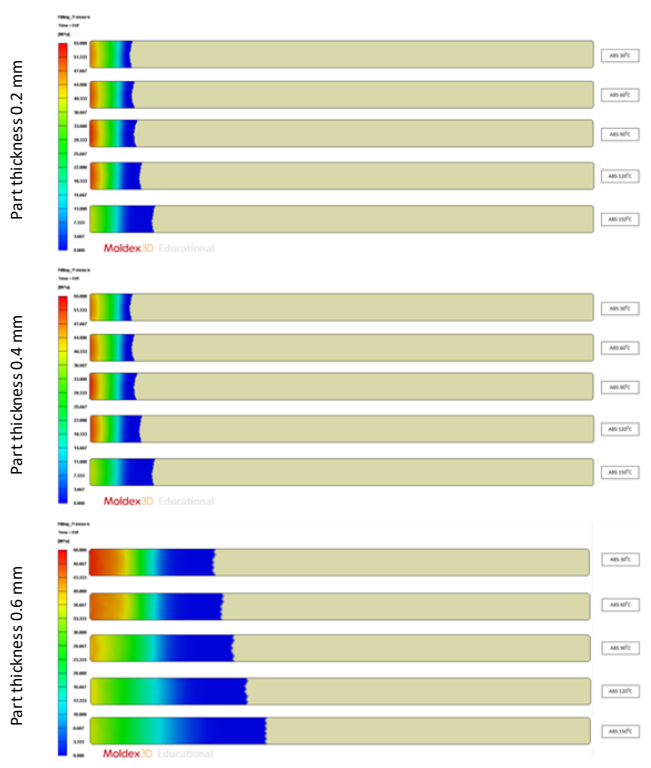

Figure 7. Melt-flow lengths measured in the simulation with the stamp temperature varying from 30 to $150{ }^{\circ} \mathrm{C}$

Table 2. Simulation and experimental results for melt-flow length under different stamp temperatures

\begin{tabular}{|c|c|c|c|c|c|}
\hline \multirow{2}{*}{} & \multicolumn{5}{|c|}{ Stamp temperature $\left({ }^{\circ} \mathrm{C}\right)$} \\
\cline { 2 - 6 } & 30 & 60 & 90 & 120 & 150 \\
\hline $\begin{array}{c}\mathrm{Si} \text { ABS_ } \\
0,2\end{array}$ & 12,51 & 13,12 & 13,88 & 15,25 & 17,36 \\
\hline $\begin{array}{c}\text { Ex_ABS_ } \\
0,2\end{array}$ & 14,54 & 14,69 & 14,85 & 15,26 & 15,8 \\
\hline $\begin{array}{c}\mathrm{Si} \text { _ABS_ } \\
0,4\end{array}$ & 23,8 & 25 & 27,9 & 30,38 & 33,37 \\
\hline $\begin{array}{c}\text { Ex_ABS_ } \\
0,4\end{array}$ & 25,56 & 26,47 & 26,86 & 27,89 & 30,24 \\
\hline $\begin{array}{c}\mathrm{Si} \text { ABS_ } \\
0,6\end{array}$ & 37,41 & 39,52 & 40,66 & 43,56 & 45,89 \\
\hline $\begin{array}{c}\text { Ex_ABS_ } \\
0,6\end{array}$ & 36,04 & 37,41 & 38,09 & 40,11 & 43,69 \\
\hline
\end{tabular}

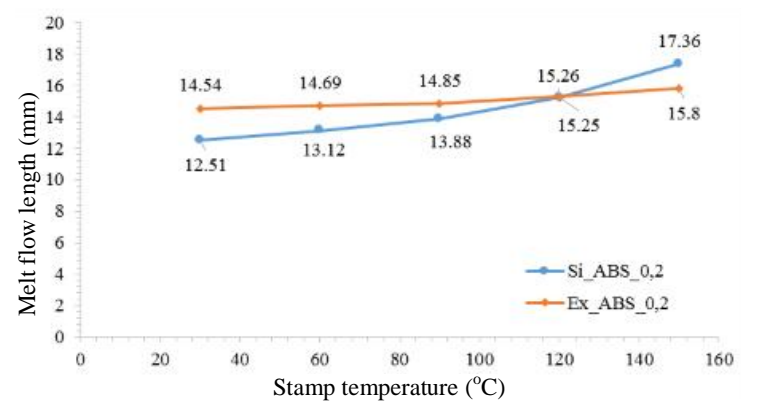

Figure 8. Comparison of the melt-flow lengths measured in the simulation and experiment with a part thickness of $0.2 \mathrm{~mm}$. 


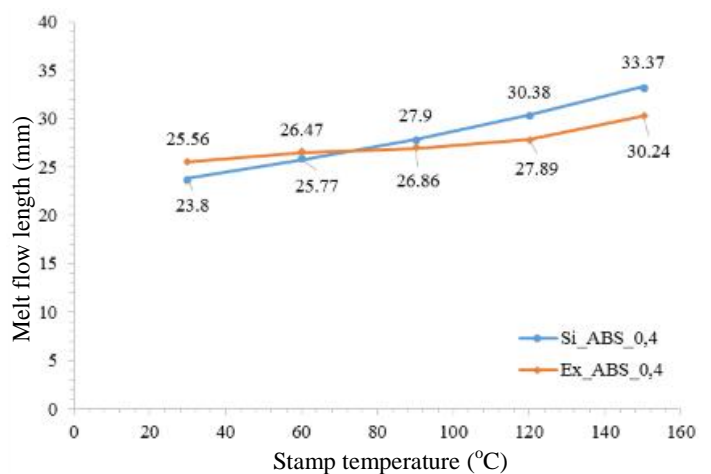

Figure 9. Comparison of the melt-flow lengths measured in the simulation and experiment at the part thickness of $0.4 \mathrm{~mm}$.

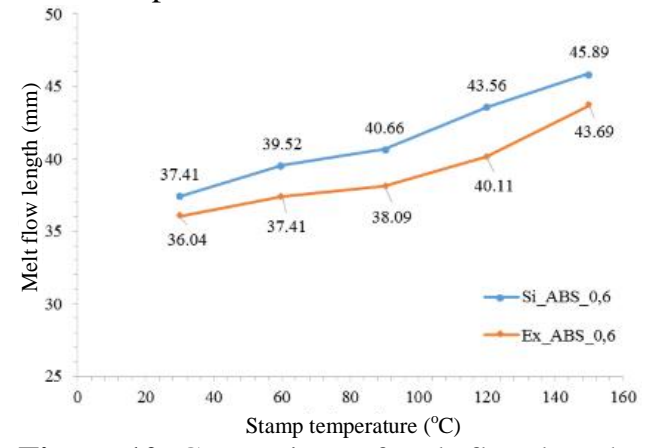

Figure 10. Comparison of melt-flow lengths measured in the simulation and experiment with a part thickness of $0.6 \mathrm{~mm}$.

\section{CONCLUSIONS}

In this study, via a simulation and experiment, the effect of the stamp temperature on melt-flow length was evaluated using different part thicknesses. In addition, by varying the stamp temperature from 30 to $150{ }^{\circ} \mathrm{C}$, the accuracy of the simulation was verified. Based on the results, the following conclusions were obtained:

$\checkmark \quad$ In the simulation, when the stamp temperature was raised from 90 to $150{ }^{\circ} \mathrm{C}$ at part thicknesses of $0.2 \mathrm{~mm}, 0.4 \mathrm{~mm}$, and $0.6 \mathrm{~mm}$, the melt-flow length increased by approximately $25.0 \%$, $19.6 \%$, and $12.8 \%$, respectively.

$\checkmark$ When the stamp temperature was higher than the glass-transition temperature of $\mathrm{ABS}$, the improvement in the melt-flow length was clearer, especially in the thinner part.

$\checkmark$ In the experiment, the positive effect of the stamp temperature was observed; however, the improvement in the melt-flow length in was slightly little different than that in the simulation.

\section{REFERENCES}

[1] D. Drummer, K. Vetter, "Expansioninjection-molding (EIM) by cavity near melt compression - About the process characteristic", CIRP Journal of
Manufacturing Science and Technology, 4, 2017, 376-381.

[2] B. Sha, S. Dimov, C. Griffiths, M.S. Packianather, "Micro-injection moulding: factors affecting the replication quality of micro features", Second International Conference on Multi-Material Micro Manufacture, 2006, 269-272.

[3] C.A. Griffiths, S.S. Dimov, D.T. Pham, "Micro injection moulding: the effects of tool surface finish on melt flow behavior", Second International Conference on Multi-Material Micro Manufacture, 2006, 373-376.

[4] D. Annicchiarico, U. M. Attia, J. R. Alcock, "A methodology for shrinkage measurement in micro-injection moulding", Polymer Testing, 32, 2013, 769-777.

[5] W. M. Yang, H. Yokoi, "Visual analysis of the flow behavior of core material in a fork portion of plastic sandwich injection molding", Polymer Testing, 22, 2003, 37-43.

[6] H. Yokoi, , N. Masuda, H. Mitsuhata, "Visualization analysis of flow front behavior during filling process of injection mold cavity by two-axis tracking system", Journal of Materials Processing Technology, 130-131, 2002, 328-333.

[7] K. Y. Lin, F. A. Chang and S. J. Liu, Using differential mold temperatures to improve the residual wall thickness uniformity around curved sections of fluid assisted injection molded tubes, International Communications in Heat and Mass Transfer, 36, 2009, 491497.

[8] S. C. Chen, P. S. Minh and J. A. Chang, Gasassisted mold temperature control for improving the quality of injection molded parts with fiber additives, International Communications in Heat and Mass Transfer, 38, 2011, 304-312.

[9] K. M. Tsai, C. Y. Hsieh and W. C. Lo, A study of the effects of process parameters for injection molding on surface quality of optical lenses, Journal of Materials Processing Technology, 209, 2009, 3469-3477. 